\title{
Speaking Spanish in the Healthcare System
}

Alfredo Palacios

\section{Introduction}

In the past 30 years, the Hispanic population has grown by 10\% in the United States, with the current percentage being about $19 \%$ of the entire US population. With the Hispanic population also being one of the groups hardest hit by conditions like COVID-19, kidney failure and type 2 diabetes, the American healthcare system has a duty to help and serve this community (U.S. 2019). However, less than $6 \%$ of all American physicians identify themselves as Spanish-speaking despite projections of Hispanic people making up a quarter of the US population by 2045 (Abuelo 2020). The lack of Spanish-speaking physicians within a country that has a such high need for them often results in the small number of Spanish-speaking physicians being overwhelmed or relying on other faculty for support they may or may not be certified to perform within a medical setting. In my study, I interviewed five native Spanish speakers to investigate the effects of language disparity between patients and healthcare providers and to see how their experiences within the medical field may have affected their views on the American healthcare system as a whole and how they believe such interactions may have affected the service they received. Based on the results I received from my participants, all five (1) believe that not speaking English as one's native language puts patients at a disadvantage in terms of receiving adequate healthcare (even with the help of translators) and (2) have an overall negative view of the healthcare system. Additionally, most believe that their lack of exposure to medical terminology in Spanish makes it hard for them to serve as effective translators for loved ones.

\section{Methods}

In my study, I aimed to gather data from a wide variety of people in order to make generalizations that better reflected the views of the entire community rather than just a particular minority. In order to do this, I gathered participants that ranged in age, English proficiency, Spanish proficiency, and country of origin. All of my interviews were conducted in person, and I remained quiet for the majority of the interview to prevent any manipulation, influence, or suggestion of the participant's answers and to allow them to be as accurate as possible. I also carefully designed the questions that I asked my participants to allow them to be as open ended as possible but still specific enough to elicit responses that had to do with the premise of my study. During each interview, I asked the following questions in this order: "Have you ever been belittled, attacked, or targeted for speaking the way that you do? Has that ever happened to you for speaking your first language?"; "Has anything like this ever happened in a medical setting?"; "Have you ever experienced a language barrier between your doctor/nurse and yourself? If so, how extensive was it and how do you think it affected the care they gave you?"; "Have you ever served as an interpreter for a loved one or someone you know? If so, how difficult was it to do this accurately?"; and finally "In what ways have these experiences affected your views on the medical field and/or healthcare system?" In addition to these questions, I also asked each participant if there was anything else they wanted to add about 
the matter in order to allow them to freely express any opinions, comments, or experiences. Furthermore, most of my initial questions had smaller follow-up questions to prompt the participant to expand on certain concepts and/or details that would aid me in my data gathering. Finally, for my participant that spoke no English, I directly translated all words into Spanish in order for her to answer the questions sufficiently.

\section{Data}

Considering that my participants varied greatly in language proficiency, age, and upbringing, I was able to receive a wide range of answers for the questions I asked. Upon being asked the first question, many of my participants recalled experiences they had in public places where they would often get ugly looks, snickers, or passive-aggressive comments when using their first language with friends and/or family, and some noticed that this was especially common in predominantly Caucasian areas. In one case, one of my participants was actually called racial slurs for using her first language as a child and would often be bullied for the way she spoke in English. However, a few of my participants said that they had never experienced such things within public spaces. When asked the second question, many of the participants responded that such things also occurred within the medical setting, with some instances being much more obvious than others. For example, in one of my interviews, the participant, who spoke Spanish as proficiently as English, described an experience she had when she had just given birth to her son. Since her son was born with acid reflux, she asked her physician what the difference was between "vomit" and "throw up" and in response to her simple question her physician ran out to get a medical translator to aid in their communication. In another case, one participant was considered to not speak English at all and was passed off to a translator before she even had a chance to speak. In another example, one participant served as a translator for her grandmother when she was eight, and because of her age she was unable to translate things correctly and would often receive confused or "funny" looks from the physician.

However, some participants reported that they do not believe they have experienced such things and that speaking Spanish was never a problem for them. After asking my interviewees the third question, many of them said that they had either experienced the language barrier personally or witnessed someone go through it as they served as a translator. Many of the participants said they had been required and expected to accurately translate advanced English and medical terminology from as early as the age of six. Additionally, when the participant was unable to translate things accurately or efficiently enough, they were often ridiculed by either their doctor or the person they were translating for. In one interview, the participant noted that when she spoke to medical faculty their attitudes would drastically change from when she spoke Spanish to when she spoke English. She claims that it would seem like "they were trying to get rid of her faster" when she spoke in Spanish and were a bit more considerate to her when she spoke her second language.

Many of the participants felt that, even today, it is very hard to translate things from a doctor to a loved one within a medical context. According to many of the interviewees, their lack of exposure to medical terminology made it very hard to translate efficiently and they usually resorted to translating only the "main points." In one case, due to lack of translation, the participant was completely unaware that she was not supposed to consume grapefruit while on her medications until about two 
weeks after they had been prescribed to her. Generally, most of the participants that have served as interpreters to their loved ones have agreed that it is very difficult to accurately translate things and affects the service they receive, particularly within a medical setting. When asked the final question, all of the participants, regardless of age, upbringing, and language proficiency, agreed that the American health system was designed in a way that prevents anyone that is not a native English speaker from receiving adequate healthcare. However, the reasoning behind this statement varied. In some interviews, the person being interviewed said that in most cases the doctors they went to spoke only English and that they therefore had to take more time to find-and then compete against other patients for appointments with - the few doctors that did speak both languages. As a result, one participant now hates going to the doctor for that reason and fears that if they had an emergency they would not be helped because of the language barrier. Another reason that some participants made this statement was because they believe the healthcare system as a whole does not do enough to support patients that do not claim English as their native language. According to one participant, "It's very unpredictable whether we will actually be helped because if there is no one on shift that knows Spanish then there is no way to communicate what I am feeling or experiencing." Others reported that usually the clinic or hospital they visit is "underprepared" in translators, which results in a "delayed" response in helping the patient. Overall, it is clear that in not having English as their native language patients have gone through many negative experiences with medical faculty that greatly affects their views on the healthcare system.

\section{Discussion}

As someone who has experienced the same things many of the participants discussed with me, my opinion was not changed by this study and was only reconfirmed by it. Many people assume that if there is a language barrier within a situation, that it is easy to pull out an electronic translator and expect everything to be communicated effectively. In reality, this is very far from the truth in that no electronic translator is ever $100 \%$ accurate let alone effective. For example, Gerrish et al. (2004) found that many patients viewed interpreting services to be inadequate and that many of the nurses were accepting of this inadequacy and prepared to rely on family members of the patient to accurately interpret for them rather than look for other ways to improve interpreting services. Additionally, a 2014 news report stated that many Latinos are discouraged from asking for help or from even understanding the healthcare information available to them (e.g., resources such as the Obamacare website) due to the language barrier (Machado 2014). In fact, there are many articles and studies that have shown direct correlations between lack of effective communication and negative overall patient experience. One such study observed the impact of the language barrier in healthcare in urban underserved Hispanic communities and it found that the language barrier correlated negatively with overall patient satisfaction (David et al. 1998). Additionally, this same study also found that this language barrier pushed many physicians to not thoroughly explain medication side effects, which correlated with less compliance with taking medications (David and Rhee 1998). However, the effects of the language barrier do not just end with low patient satisfaction but actually manifest themselves in a profound effect on the patient's health. In a 2010 study, data found that language barriers play a large role in health disparities among Latinos, especially with diabetes (Fernandez et al. 2011). In fact, the study even claims that limited English proficiency can 
be used as a predictor for poor glycemic control among insured Latinos within the US (Fernandez et al. 2011). However, it is not only the patients but also many faculty who see language barriers as a problem when addressing health concerns. In a small study performed at a hospital, 95\% of all nurses believed that the language barrier is an impediment to quality care, while $88 \%$ of physicians said they believed the same thing (Bernard et al. 2006). This is not helped by the fact that only about $6 \%$ of all physicians identify as bilingual while the Spanish-speaking population continues to grow at an exponential rate within the US

(Abuelo 2020). Sadder still, it seems that some medical institutions are not willing or cannot afford to make changes to aid non-English speaking patients. As stated above, many workers usually expect a family member of the patient to provide translation rather than trying to improve interpreting services that have been shown to be inadequate (Gerrish et. al 2014).

For example, one article described how faculty would often rationalize against the need for Spanish-speaking healthcare professionals with such excuses as "Spanish, like medical terms, is based on Latin and therefore Spanish speaking patients should be able to understand the terminology"; "Usually Latino patients have a family member who can interpret and therefore I do not need to learn it"; or "Spanish is too difficult and I am too busy" (Bennink 2013). In many cases, the patients are blamed for not knowing English, which leads to further discrimination toward these groups since language is the means by which the patient accesses healthcare, learns about its services, and makes decisions about their behavior (Bennink 2013).

The data that I gathered from my interviews and that which was gathered from the studies above,

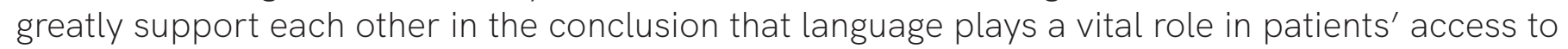
healthcare and their overall views of it. It is clear that this country's healthcare system is not suited well enough to provide adequate services to those who do not have English as their first language, which leads to disproportionately low rates of healthcare visits and patient satisfaction.

Spanish-speaking communities are projected to continue growing over the next few decades, and it is time for the healthcare system to accept this and make accommodations for a future that isn't solely Anglophonic.

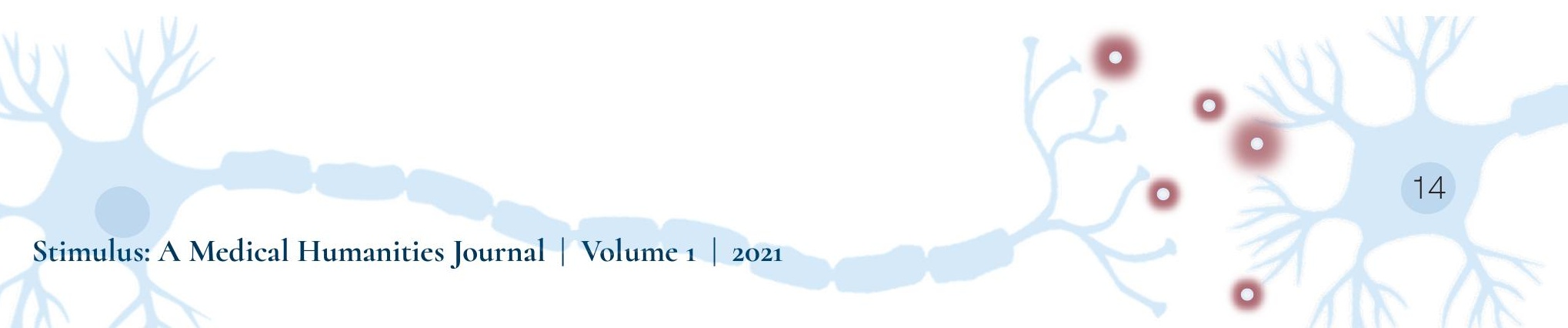




\section{Works Cited}

Abuelo, Carolina. "The U.S. Needs More Spanish-Speaking Doctors." 2020. U.S. News \& World Report, August 25, 2020. https://www. usnews.com/news/healthiest-communities/articles/2020-08-25/why-we-need-more-spanish-speaking-doctors

Bennink, Ashley. "Why Is Spanish for Healthcare Professionals Important?" 2013. Ayuda, Doctor, May 22, 2013. https://ayudadoctor.wordpress.com/2013/05/22/why-is-spanish-for-healthcare-professionals-important/

Bernard, Andrew, Misty Whitaker, Myrna Ray, Anna Rockich, Marietta Barton-Baxter, Stephen L. Barnes, Bernard Boulanger, Betty Tsuei, and Paul Kearney. 2006. "Impact of Language Barrier on Acute Care Medical Professionals Is Dependent Upon Role." Journal of Professional Nursing 22 (6): 355-358. https://doi.org/10.1016/j.profnurs.2006.09.001

David, R. A., and M. Rhee. 1998. "The Impact of Language as a Barrier to Effective Health Care in an Underserved Urban Hispanic Community." The Mount Sinai Journal of Medicine 65 (5-6): 393397.

Fernandez, Alicia, Dean Schillinger, E. Margaret Warton, Nancy Adler, Howard H. Moffet, Yael Schenker, Vicotira Salgado, Ameena Ahmed, and Andrew J. Karter. 2011. "Language Barriers, Physician-Patient Language Concordance, and Glycemic Control Among Insured Latinos with Diabetes: The Diabetes Study of Northern California (DISTANCE)." Journal of General Internal Medicine 26 (170-176). https://doi.org/10.1007/s11606-010-1507-6.

Gerrish, Kate, Ruby Chau, Abi Sobowale, and Elizabeth Birks. 2004. "Bridging the Language Barrier: The Use of Interpreters in Primary Care Nursing." Health and Social Care in the Community 12 (5): 407-413. https://doi.org/10.1111/j.1365-2524.2004.00510.x

Machado, Amanda. 2014. "Why Many Latinos Dread Going to the Doctor." The Atlantic. May 7, 2014. www.theatlantic.com/health/archive/2014/05/why-many-latinos-dread-going-to-the-doctor/361547/

U.S. Department of Health and Human Services. Centers for Disease Control and Prevention. 2019. "Hispanic/Latino Americans and Type 2 Diabetes." Centers for Disease Control and Prevention, September 15, 2019, www.cdc.gov/diabetes/library/features/hispanic-diabetes.html 